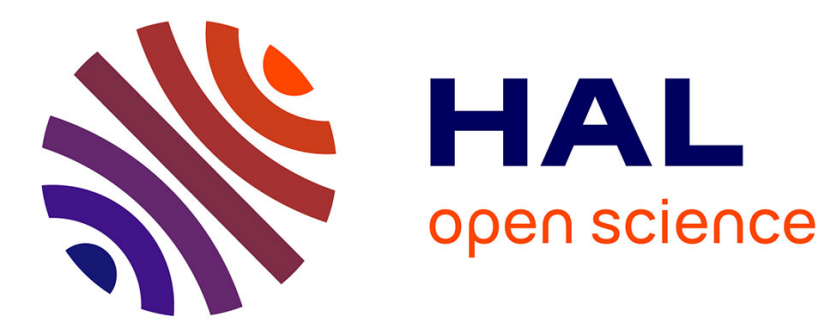

\title{
PHOTOELECTRICAL PHENOMENA AT THE ICE-SEMICONDUCTOR INTERFACE
}

\author{
V. Chesnakov, V. Petrenko, I. Ryzhkin, A. Zaretskii
}

\section{To cite this version:}

V. Chesnakov, V. Petrenko, I. Ryzhkin, A. Zaretskii. PHOTOELECTRICAL PHENOMENA AT THE ICE-SEMICONDUCTOR INTERFACE. Journal de Physique Colloques, 1987, 48 (C1), pp.C199-C1-103. 10.1051/jphyscol:1987114 . jpa-00226258

\section{HAL Id: jpa-00226258 https://hal.science/jpa-00226258}

Submitted on 1 Jan 1987

HAL is a multi-disciplinary open access archive for the deposit and dissemination of scientific research documents, whether they are published or not. The documents may come from teaching and research institutions in France or abroad, or from public or private research centers.
L'archive ouverte pluridisciplinaire HAL, est destinée au dépôt et à la diffusion de documents scientifiques de niveau recherche, publiés ou non, émanant des établissements d'enseignement et de recherche français ou étrangers, des laboratoires publics ou privés. 


\title{
PHOTOELECTRICAL PHENOMENA AT THE ICE-SEMICONDUCTOR INTERFACE
}

\author{
V.A. CHESNAKOV, V.F. PETRENKO, I.A. RYZHKIN and A.V. ZARETSKII \\ Institute of Solid state Physics, The USSR Academy of \\ Sciences, Chernogolovka 142432, USSR, Moscow District
}

\begin{abstract}
Résumé - L'influence de la lumière sur le courant continu traversant I'interface glace-CdSe a été mise en évidence. On propose un nouveau modèle de la conductivité électrique basé sur le transfert des électrons par des défauts ioniques.
\end{abstract}

Abstract - A strong influence of light illumination on the direct current flowing through an ice-CdSe interface was detected. A new model of electric conductivity of ice based on "relay-race" transfer of electrons caused by ionic defects is proposed.

\section{INTRODUCTION}

Ice is one of the most well known and wide-spread materials that have a protonic conductivity $/ 1,2 /$. When studying its electrical properties there arises a problem of the charge-exchange between ice and electrodes since most electrodes have an electronic conductivity. In our experiments we studied the processes of charge exchange at electronic conductor-ice interfaces. A strong influence of light illumination on the currents flowing through ice-CdSe interface was detected. The illumination does not influence the electrical properties of metal-ice interfaces but generates fast decaying photoresponses on interfaces of ice and several others semiconductors besides $\mathrm{CdSe}$ ( $\mathrm{Si}, \mathrm{Ge}, \mathrm{Cu}_{2} \mathrm{O}, \mathrm{ZnO}, \mathrm{ZnSe}$ ). A new model of electric conductivity of ice based on "relay-race" transfer of electrons by ionic defects is proposed here in to explain the observed phenomena.

\section{EXPERTMENTAL TECHNIQUE}

The undoped ice, used in our experiments, was grown from deionized and degassed water as in $/ 3 /$. Fig. 1 shows an ice sample with a guard ring and two electrodes (semiconductor and metallic). We employed the following semiconductors : $n$-Si (the impurity concentration $\left.\sim 10^{22} \mathrm{~m}^{-3}\right) ; \mathrm{p}-\mathrm{Si}\left(\sim 10^{21}\right.$ and $\left.10^{19} \mathrm{~m}^{-3}\right) ; \mathrm{p}-\mathrm{Ge}\left(\sim 10^{21} \mathrm{~m}^{-3}\right)$ ; n-CdSe (the resistivity being $3 \cdot 10^{-3}$ (Ohm.m)-1 at room temperature); n-ZnSe

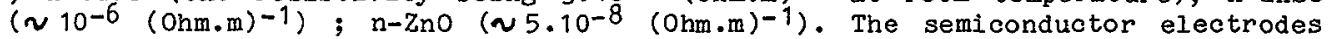
ceasuring $4 \times 6 \times 2 \mathrm{~mm}$ were used in the experiments. Before the experiment CdSe and ZnSe electrodes were chemically polished in $\mathrm{CrO}_{3}+\mathrm{HCl}$; $\mathrm{Si}$ was polished in $\mathrm{HF}+7 \mathrm{HNO}_{3}$ and $\mathrm{Ge}-$ in $\mathrm{CP}-4 \mathrm{~A}$; $\mathrm{ZnO}$ was polished only mechanically with diamond paste. Ohmic indium contacts were soldered on electrodes (the current-voltage characteristics of the contacts obeyed Ohm's law). The second electrode was a stainless-steel circular disc, $10 \mathrm{~mm}$ in diameter. The disc has an opening in the centre (of about $1 \mathrm{~mm}$ ) through which the ice- semiconductor interface could be illuminated. A stainless-steel guard ring was placed around the metallic electrode in order to eliminate the surface component of the electric current.

No photoeffect was observed under illumination of the stainless steel-ice interface. An ice sample $\left(20 \times 20 \times 2 \mathrm{~mm}^{3}\right)$ with electrodes (the C-axis of the ice being perpendicular to the planes of the electrodes) was placed in a cryostat, provided 
with a quartz window. The cryostat was cooled by nitrogen vapors. The thermoregulation system enabled us to carry out the measurements within 173-273 K. The light sources were a pulsed nitrogen laser ( $\lambda=337 \mathrm{~nm}$, light pulse duration

$\tau \sim 10^{-8} \mathrm{~s}$, pulse power $\mathrm{N}_{\mathrm{p}} \sim 1.6 \mathrm{~kW}$, pulse frequency $\mathrm{f}=10-100 \mathrm{~Hz}$ ), a continuous He-Ne laser $\left(\lambda=633 \mathrm{~nm}\right.$, power $\mathrm{N}=2 \cdot 10^{-3} \mathrm{~W}$ ) and a high presure xenon lamp (continuous spectrum, integral power $N \sim 200 \mathrm{~W}$ ). A prism monochromator was used to assess the spectral dependences. The electrical signals were recorded using an oscilloscope and electrometer, $a X-Y-$ recorder and a lock-in nanovoltmeter. The scheme of measurements is presented in Fig. 1.

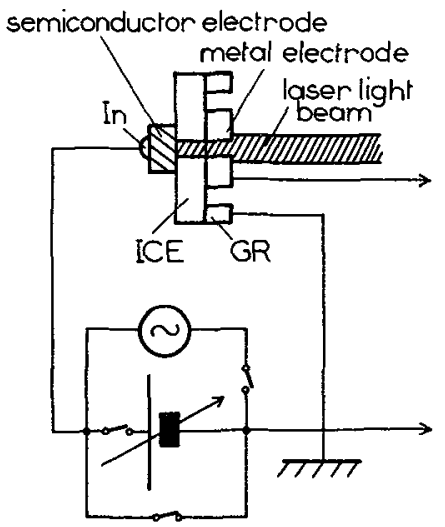

Fig. 1 - Arrangement of the ice sample and the electrodes, and scheme of the electrical measurements.

\section{RESULTS}

The photoeffect observed in this work depends on the fact that continuous illumination of the ice-CaSe interface gives rise to the electric current in the circuit even in the absence of the external voltage source ( $\left.U_{e x}=0\right)$. Fig. $2 b$ demonstrates the response of this system to He-Ne laser illumination.

There are two characteristic regions : fast photoresponce ( $\tau \simeq 1$ s), which takes place when switching on or off the illumination and the photosignal, which is constant during the experiment $\left(t \sim 10^{-3} s\right)$. The fast photoresponse is relevant for all semiconductors listed above (fig. 2a). Its amplitude is positive for n-type semiconductors used in our experiments and negative for $p$-type semiconductors (nitrogen laser-pulse illumination). Fig. 3 shows spectral dependences for some semiconductors. Long waves limits of photoresponse correspond to energy gaps of semiconductors. Continuous photosignal is observed for CdSe only. This case is a matter of interest as it is connected with the charge exchange at the interface. Figure 4 demonstrates the spectral dependence of the photosignal, normalized to the xenon-lamp spectrum, from the CaSe-ice interface for three values of the external voltage : $\mathrm{U}_{1}=0 ; \mathrm{U}_{2}=+30 \mathrm{~V} ; \mathrm{U}_{3}=-30 \mathrm{~V}$ (plus sign corresponds to the positive potential on the semi conductor.

Fig. 5 shows the current-voltage characteristics of the CdSe-ice-metal system under the He-Ne laser illumination (open circles) and in the dark (closed circles). The illumination reduces the resistivity, when the external voltage is positive. The current was equal to zero (less than $10^{-10_{A}}$ ) for all other semiconductors. The frequency dependences of the conductivity and of the dielectric permeability of the CdSe-ice-metal system are shown in fig. 6. The He-Ne-laser illumination increased reversibly the low frequency $(3-20 \mathrm{~Hz})$ conductivity and decreased the low frequency dielectric permeability of the system (alteration was about 10\%). The illumination of Au, Pt, Pd and In metallic electrodes gave no photosignals. 

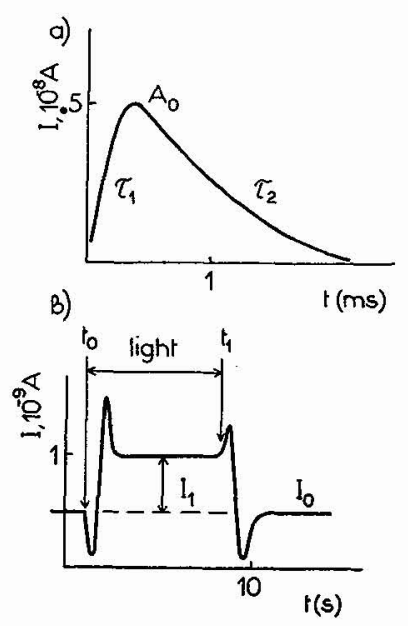

Fig.2. a) Oscillogram of the semiconductor-ice-metal system response to a nitrogen laser light pulse: A - signal amplitude $\tau_{1}{ }^{\circ}$ - time of the signal increase $\tau_{2}$ - time of the sigmal decrease

b) Response of the system, comprisong a Case electrode, to continuous illumination: $t_{0}$ - time of the laser switch on

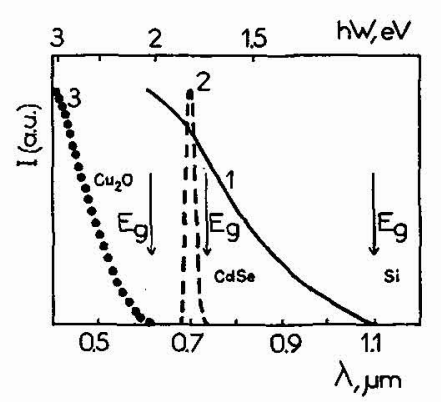

Fig. 3. Spectral dependences of the photosignal for some semiconductors.

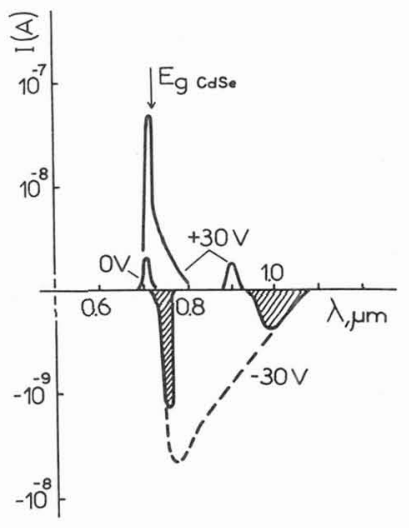

Fig.4. Spectral dependences of the photosigmal for the CaSe-ice-metal system for three extermal voltages: $\mathrm{U}_{1}=0 \mathrm{~V} ; \mathrm{U}_{2}=+30 \mathrm{~V} ; \mathrm{U}_{3}=-30 \mathrm{~V}$ (for $-30 \mathrm{~V}$ : dotted Ifne-the fast photoresponce, hatching spectrum-continuous photoaignal; for $U>0$ the fast response is approximately equal to the continuous photosignal). 


\section{DISCUSSION}

From our point of view the main result is observation of the continuous photosignal, which takes place under illumination of ice-CoSe interface, since the ability of the direct current to flow through the ice-semiconductor interface is not obvious. One can be confident that it is not the intrinsic photoconductivity of ice that causes the photosignal occurrence. In specially conducted experiments the bulk of the ice sample was illuminated in the interelectrode region. When the electrodes were in the dark, photosignal is not observed. The fact that no photosignal was present when a semiconductor was replaced by gold, platinum, palladium and indium also provides evidence against the hypothesis of intrinsic photoconductivity of ice. It is unlikely that we deal with an external photoeffect in our experiments, since illumination of In-ice interface yields no photosignal (of all the materials used, including semiconductors, In has a minimal work function $-3.8 \mathrm{eV}$ ). The spectral dependences (fig. 3), which have a "red" limit, coincident with the band gap of the corresponding semiconductor, suggest that photosignal is due to electrons and holes photogenerated in the semiconductor and their separation under electrical and "diffusional" forces. The available experimental data and the techniques employed do not give sufficient grounds for a precise description of the processes determining the continuous photosignal. We believe that no hydrogen and oxygen are liberated during the current flow under the illumination. Simple estimations of the charge which passed through the interface $\left(I \sim 10^{-8} \mathrm{~A}, t \sim 10^{-3} \mathrm{~s}\right.$ ) predict a yield of about 100 atomic layers of gas. The yield of such a quantity of gas should cause the electrode separation or, at least, a irreversible change of the electrical properties of the contact, which was not actually observed. The gas diffusion is unlikely to be of importance because of small diffusion coefficients of $\mathrm{H}_{2}$ and $\mathrm{O}_{2}$ (DN $\left.1.0^{14} \mathrm{~m}^{2} \mathrm{~s}^{-1} / 4 /\right)$. Now, we shall describe some models of the continuous photosignal.

\section{MODEL OF BOUND ELECTRON STATES IN ICE}

According to the modern concepts, electrical current in ice is determined by the movement of protonic charge carriers of four types of ionic $\left(\mathrm{H}_{3} \mathrm{O}^{+}, \mathrm{OH}^{-}\right)$and orientational (D,L) defects. Thus the motion of electrons does not play any role. However, the inclusion of electrons into consideration is of great interest. Moving a proton along the bond in the ideal ice structure, one can obtain two defects $-\mathrm{H}_{3} \mathrm{O}^{+}$ and $\mathrm{OH}^{-*}$ - with the charge equal to $+0.62 e$, respectively $/ 5 /$, where e is a proton charge. It is quite natural that the bond of the electron with the water molecule, that loses one proton, is getting weaker. Hence the energy level of this electron is placed within the band gap of ice. Now, let us consider the situation when a proton move with an electron along the vond in the ideal ice structure. We obtain a new pair of defects $-\mathrm{H}_{3} \mathrm{O}^{-}$and $\mathrm{OH}^{+}$- with the charges equal to $\pm 0.38 \mathrm{e}$, respectively. It is natural to suppose, that energy level corresponding to bond energy of the electron with $\mathrm{H}_{3} \mathrm{O}^{-}$-ion is also placed within the band gap. A similar consideration for orientational defects gives us $\mathrm{D}^{-}$and $\mathrm{L}^{+}-\operatorname{defects}$ besides usual $\mathrm{D}^{+}$ and $L^{-}$(the upper sign corresponds to the sign of the defect charge). It is convenient to use the system of four electron levels, which are placed within the band gap of ice : $\mathrm{H}_{3} \mathrm{O}, \mathrm{OH}, \mathrm{D}$ and $\mathrm{L}$. If, for example, $\mathrm{H}_{3} \mathrm{O}$-level is occupied we deal with $\mathrm{H}_{3} \mathrm{O}^{-}$-ion, if not - we deal with $\mathrm{H}_{3} \mathrm{O}^{+}$. The same is true for $\mathrm{OH}$, $\mathrm{D}$ and $\mathrm{L}$. It is

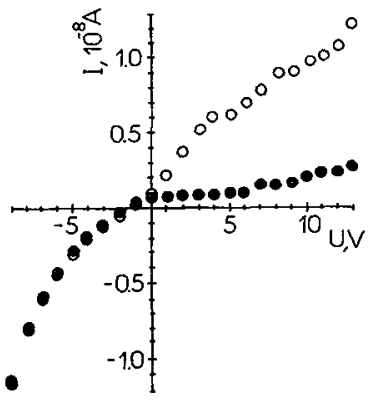

Fig.5. Current-voltage characteriatics of the CdSeice-metal system under illumination (open circles) and without it (dark circles), He-Ne laser, $\mathrm{T}=-10^{\circ} \mathrm{C}$. 


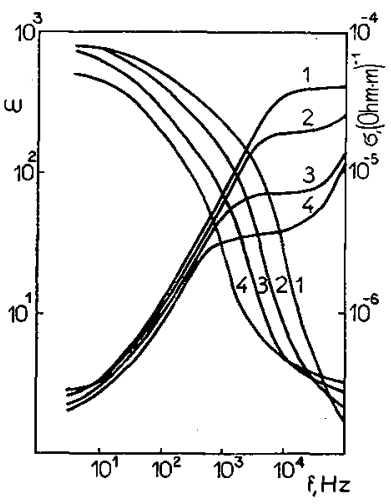

Fig.6. Dispersion curves $\sigma(f)$ and $\varepsilon(f)$ of the CdSe-ice-metal system several temperatures: $T_{1}=-9^{\circ} \mathrm{C}$, $\mathrm{T}_{2}=-17^{\circ} \mathrm{C}, \mathrm{T}_{3}=-27^{\circ} \mathrm{C}, \mathrm{T}_{4}=-34^{\circ} \mathrm{C}$.

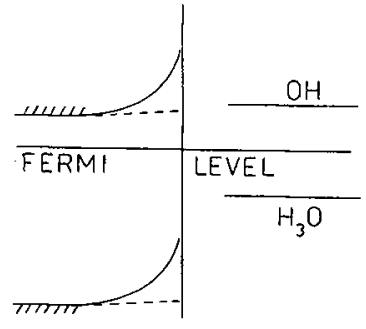

case

ICE
Fig.7. Reciprocal disposition of energy levels of electrons in ice and in the semiconductor (Case) under illumination (dotted line) and without it.

very difficult to show an exact position of these levels within the band gap. We can suggest only a very rough estimation in the case, when we suppose, that the system of electron-defect is the hydrogen-like one. In this case we obtain that the bound energy of the electron with $\mathrm{OH}^{-}$-ion equals to $\mathrm{E}_{\mathrm{OH}}\left(\sim \mathrm{E}_{\mathrm{D}}\right) \sim 2$ eV and $\mathrm{E}_{\mathrm{H}_{3} \mathrm{O}}\left(\sim \mathrm{E}_{\mathrm{L}}\right) \sim$ $5.2 \mathrm{eV}$, if $\varepsilon=1$. It is very interesting to consider the situation with four ions only : $\mathrm{H}_{3} \mathrm{O}^{+}, \mathrm{H}_{3} \mathrm{O}^{-}, \mathrm{OH}^{+}, \mathrm{OH}^{-}$. It is clear that due to these carriers the direct current can flow in ice (for this purpose $B$ jerrum added to $\mathrm{H}_{3} \mathrm{O}^{+}$and $\mathrm{OH}^{-}$the orientational defects). Thus we can renounce the point of view connected with $D$ and $\mathrm{L}-$ defects and suppose, that in practice $\mathrm{OH}^{+}$and $\mathrm{H}_{3} \mathrm{O}^{-}$-ions exist instead of $\mathrm{D}$ and $\mathrm{L}$. The orientational defect concentration is larger than ionic one in pure ice, consequently we must suppose, that $\mathrm{OH}$ and $\mathrm{H}_{3} \mathrm{O}$ electron levels are placed above and below Fermi level respectively. The ratio of these concentrations gives us the distance between $\mathrm{OH}$ and $\mathrm{H}_{3} \mathrm{O}$ levels of about $0.3 \mathrm{eV}$. This model of bound electron states in ice gives one a possibility to propose a new way of charge exchange between ice and electronic conductors. $\mathrm{H}_{3} \mathrm{O}^{+}$, for example, moves towards the negative electrode. After capturing an electron from the electrode it is transformed into $\mathrm{H}_{3} \mathrm{O}^{-}$and begins to move in the opposite direction. Having approached the positive electrode $\mathrm{H}_{3} \mathrm{O}^{-}$gives an electron to it changing again into $\mathrm{H}_{3} \mathrm{O}^{+}$. Similar considerations are valid for the $\mathrm{OH}^{+}$and $\mathrm{OH}^{-}$pair. Thus the existence of stationary current is possible without irreversible changes of the system. The charge exchange intensity depends on the interface state, the reciprocal position of the energy levels of electrons in ice and in the electrodes and the quantity of electrons on these levels (and hence the illumination). Fig. 7 shows the reciprocal position of energy levels of electrons in ice and in CdSe (polarity of the fast photosignaI determines the direction of the bond curves in the semiconductor, the possibility of strong influence of the surface states does not allow to determine the behaviour of electron levels in ice not far from interface). More detailed discussion of the model of bound electron states in ice will be published subsequently.

\section{References}

/1/ Decroly J.C., Granicher H. and Jaccard C., Helv. Phys. Acta, 30 (1957) 465.

/2/ Workmann E.J., Truby F.K. and Drost-Hansen W.,Phys. Rev., 94 (1954) 1073.

/3/ Petrenko V.F., Whitworth R.W. and Glen J.W., Phil. Mag. B, 47 (1983) N3, pp. 259-278.

14/ Hobbs P.V., Ice Physics, Clarendon Press, Oxford (1974).

/5/ Hubman M., Z. Phys., B32 (1979) 127. 